\title{
LATIN AMERICAN IMMIGRANT MOTHERS IN SPAIN: PERCEIVED CHALLENGES AND OPPORTUNITIES
}

\author{
ELIZABETH BERROCAL ${ }^{1}$
}

\begin{abstract}
This paper reports on interviews with 13 mothers and expectant mothers who had immigrated from Latin American countries and were living in Asturias, Spain. The purpose of the study was to investigate the Latinas' postimmigration perceptions, attitudes, and experiences. Qualitative analysis revealed several themes in the women's interview responses. Two of those themes - postimmigration challenges and opportunities found in Spain-are the focus of this paper. Evidence of three main types of challenge and three main types of opportunity is provided based on the Latinas' responses. A discussion section follows, relating the women's perceptions of challenges and opportunities to circumstances in Spain and differences in Spanish and Latin American cultures and societies.
\end{abstract}

KEYWORDS: Spain, immigration, racism, education, crime, gender equality

\section{INTRODUCTION}

In developed nations, the number of female immigrants has been on the rise since 1960; by 1990, nearly 52\% of all migrants in Europe were women and girls (Zlotnik 2003). In Spain, the economic downturn that began around 2008 resulted in more emigrants leaving than immigrants entering the country; however, a reinvigorated Spanish economy has resulted in that trend being reversed. In the year 2013, there were 280,772 immigrants to Spain, but by 2017 this figure had increased to 532,482, with women accounting for 48.8 percent of that number (Instituto Nacional de Estadística 2018). As of 2017, the total

1 Elizabeth Berrocal is a doctoral student at the University of Oviedo, Oviedo, Asturias, Spain; e-mail: eberroca12020@gmail.com. 
number of immigrants in Spain was almost six million, about half of them women (Eurostat 2019; Datosmacro.com n.d.)

Among the many countries of origin for Spanish immigrants, Latin American countries have contributed and continue to contribute a substantial number. In 2017, for instance, individuals emigrating from the Latin American countries of Colombia, Ecuador, Honduras, and Peru with Spain as their destination numbered 34,210, 31,468, 18,234, and 13,936, respectively (Instituto Nacional de Estadística 2018). Though there are many differences among Latin American nations, the region in its entirety exhibits some broad cultural commonalities that tend to characterize immigrants that originate there. Similarities include a chauvinistic culture with a strong family orientation, and a culture that assigns a great deal of importance to strong family bonds. Emphasis is placed on the traditional family roles of motherhood, in particular those of marriage and childbearing, with Latin American women (Latinas) tending to transition from marriage to motherhood more rapidly than their European counterparts (Wildsmith - Raley 2006). For generations, it has been engrained in women that they are expected to fulfill the combined roles of being a good housewife, mother, and daughter. Traditionally, women are expected to stay home to attend to their children and provide them with social and emotional support; keep the home clean, tidy, and hygienic; do the necessary shopping for food and household items; and prepare the family's meals (Gonzalez-Juarez et al. 2014).

The similarities that characterize the cultural background of Latina immigrants, especially in regard to their strongly culturally determined marital and maternal roles, suggest the appropriateness of considering, as a group, Latina immigrants to Spain who are mothers and expectant mothers. This paper reports the results of a study in which a sample of 13 Latina immigrants to Spain who had given birth after their arrival or were pregnant were interviewed to investigate their post-immigration perceptions, attitudes, and experiences. The women were asked questions about their reasons for immigrating; birth-related decisions; their economic-, family-, and social situations; and their experiences since immigrating. The paper focuses on the post-immigration challenges the Latinas reported and the opportunities they perceived to be present in their new home country. It thereby provides a recent, evidence-based picture of Latina immigrant mothers and expectant mothers with regard to their perceived challenges and opportunities in Spain. Following this introduction, the paper is divided into four main parts: Methodology, Immigrant Latinas' Challenges, Immigrant Latinas' Opportunities, and Discussion. 


\section{METHODOLOGY}

The criteria for inclusion in the study were defined as being a woman who had immigrated to Spain from Latin America, and who had given birth to a child in Spain or was pregnant at the time. The study used purposeful sampling to develop a sample that met the participant criteria and was potentially rich in the sought-after information (Patton 2002). The study took place in the Asturias principality of Spain. Study participants came from locations where immigrant women who were pregnant or had one or more young children were believed to congregate. These included organizations in three Asturias cities. In Gijon, three participants were located at Casa de Acogida Para Madres Getantes, a residence for unwed mothers run by the Catholic Diocese in Spain. In Aviles, nine participants were located at Centro de Acogida, where women seek resources and information regarding community services. In Oviedo, one participant was located at Red Madre, a nonprofit organization that helps expectant mothers and mothers of children two years old or less with social services and some material assistance. A total of 13 Latinas with a median age of 27 years made up the sample. These participants had immigrated to Spain from six different Latin American countries: Brazil, Colombia, Dominican Republic, Ecuador, Guatemala, and Peru. Each of the women sat for one audiorecorded semi-structured interview, with the same set of questions guiding all interviews. Follow-up questions were asked in some cases. Sessions lasted from 30 to 45 minutes.

All participants underwent an informed consent process to ensure the protection of their identity and to explain the study's purpose. The participants were advised that they would remain anonymous and that they could stop at any time there was discomfort with the interview process. They were asked for and gave permission for their interviews to be audio recorded. To help motivate the Latinas, they were each encouraged to utilize the opportunity to share their personal story.

After the audio-recorded interviews were transcribed into hard copy format, qualitative analysis was conducted to determine codes and themes reflected in interview responses. Each interview was reviewed multiple times, using inductive analysis to determine codes reflected in the Latinas' responses (Creswell - Plano Clark 2007). Following the determination of codes, several additional reviews were then undertaken to detect themes the codes had revealed. Based on the codes, eight themes were identified in the Latinas' responses to questions. Two themes that are particularly relevant for the purposes of this paper are Challenges in Spain and Opportunities in Spain. These two themes are explored in the remainder of the paper. 


\section{CHALLENGES IN SPAIN}

Qualitative analysis revealed that the interviewed Latinas had encountered a number of post-immigration challenges. The majority of those challenges fell into three main categories: personal and relationship challenges, economic challenges, and being subjected to racism and stereotyping.

\section{Personal and Relationship Challenges}

One of the most widespread difficulties mentioned by the Latinas was being a single mother and receiving no or little assistance from the biological father of her child or children. Only two participants lived with their child's or expected child's father. Participant 12 was one who indicated the difficulty she found in being a single mother alone in Spain.

P12: On occasions I get frustrated because I want to do everything right, but I don't have help from anyone.... I am alone and for me a lot of times it is difficult. I have to take care of everything myself.

Participant 4 was also caring for her child without the father's aid. When talking about having learned that the father already had a family, she referred to how she had become resigned to having a child on her own.

P4: I met him at a party, and we started dating. Further along when I got pregnant, I found out how old he was and that he had a family in Colombia. That was very hurtful but there was nothing I could do.

Participant 8 revealed that she had not initially been accepted by her husband's Spanish family and that her child's father had left them eight days after the child was born. When she was asked whether her partner was Spanish, she replied as follows.

P8: Yes. He's a Spaniard and his mother would tell him I was going to take advantage of him because I was foreign. The baby was born on [date redacted]. The baby was not even eight days old when he, my expartner, left the house. He, my ex-partner, put in the divorce petition and we separated. The baby has gone fourteen months without seeing his father. He does not know his father, and it hurts very much because his first word was "dad." 
Participant 10 also had a problem being accepted by her partner's family. She reported that though she was supported by her partner during her difficult pregnancy, she was not supported by his family.

P10: At six and a half months I went to the doctor and I was told there was a problem with the amniotic fluid. The baby was not growing like it should have. We had to spend a lot of money on private doctors and I got very worried. I was told the baby could be born with Down syndrome. It was a huge battle. I suffered a lot, because I did not have support from the father's family.... Things are better now but I went through a very hard time because I couldn't understand why the father's family would treat me so badly. I had to go to a psychologist.... If I had parents in Brazil, I wouldn't be here. I don't have a mother or father, only siblings. It is very difficult to live without any support in a country that is not yours. Now my mother-inlaw likes my child, but not that long ago she would belittle him.

Later, Participant 10 reported that at the time of the interview she was not living with her partner. Though her partner's family had accepted her child, they had not accepted her and would not allow their son to live with her.

\section{Economic Challenges}

Almost all of the interviewed immigrant women had encountered economic difficulties since their immigration. These included the three who were living at Casa de Acogida shelter, and most of the other Latinas were also economically struggling. The women who worked generally did so in low-paying jobs. This may be expected because many Latinas who immigrate to Spain do so to enter domestic service (Rodríguez-Ibáñez 2006). As of 2008, over 64 percent of female Latin American immigrants to Spain were employed in the generally low-paying areas of household services, accommodation and food preparation, and other tertiary services (Di Bartolomeo et al. 2008).

Some of the Latinas in this study were receiving public aid, while others reported being unable to qualify for such aid due to not having documentation. For instance, Participant 13, who lived with her mother and daughter, remarked on her lack of documentation.

P13: Living here is complicated. Work is a difficult subject and also obtaining documents. I asked for help, but they will not give me any because I do not have documents. 
As noted above, most of the Latinas were estranged from the father of their child or children. All of these women indicated that they received no or insufficient monetary assistance from the absent father. Participant 8 , in response to being asked whether her former partner was helping her, stated:

P8: I don't have a stable job; I don't have a steady income ... I have to find my way in life ... He gives me 150 euros, which is what the divorce settlement stipulated. He thinks the baby eats air because 150 a month is nothing. The baby's food, diapers, and those things - that money is not enough for everything.

Participant 10, who lived alone with her 14-month-old son, spoke of the difficulty of finding a job due to not having a vehicle and having no flexibility to work shifts due to having to take care of her child.

P10: It is also very difficult to find a job. Many require transportation, but I don't have a vehicle. Others require shift-related flexibility and I don't have much because of my child.

Other participants told of working in what were very likely low-paying jobs. Participant 4 was one who had recently worked as a personal carer.

P4: I was working until three days ago, the lady I was taking care of passed away. I now have to look for another job to continue to take care of my daughter.

In addition, Participant 7 stated, "If someone calls me for cleaning, I will do it." Participant 8 remarked, "I look for work too, whatever; clean plates, clean houses, clean the elderly...I don't care, whatever comes up." Participant 13 revealed that although she was undocumented, she had found a job caring for children.

Two of the interviewees spoke of the exploitation of female Latin American immigrants that also sometimes occurred. Participant 2 referred to the acceptance of work conditions by Latinas as a factor that makes them more vulnerable to exploitation.

P2: As a matter of fact, there are corporations that prefer Latin workers, and not because they pay less, but because we Latin women work better. We are fighters and don't complain, although truthfully this is also bad because we give them the ability to exploit us. 
Remarks by Participant 8 suggested that she may have been a target of exploitation at work.

P8: Sometimes for work, one has to turn the other cheek and continue. If you have a job and they exploit you, because sometimes you get exploited at work too, we put up with it because you have to support your household and your child.

It was clear from the interviews that, in one way or another, the women had found ways to make do with what monetary resources they had. These ways included working at low-wage jobs, living in a residence supported by charitable donations, living with a mother or grandmother, receiving public assistance, and, in some cases, receiving some money from their child's father. Only two of the 13 Latinas that were interviewed seemed to have economic resources that permitted them to live at above subsistence level. For most, economic security appeared to be a daily challenge.

\section{Racism and Stereotyping}

Another challenge reported by several of the participants was experiencing prejudice in the form of racism and stereotyping. Participant 10, when asked whether Latin American women were stereotyped in Spain, answered as follows.

P10: Yes, many think we came to take advantage of them. Others insult you directly, and others take advantage of you, and when they don't need you anymore, they ignore you.

Participant 11 had also encountered racist attitudes.

P11: There are racist people. Not that long ago I was at a bus stop and there were some guys who were passing out tickets to go eat at a pizzeria. The guys who were passing those things were only doing it among Spanish folks.

Participant 8 believed that her mother-in-law's racist attitude toward her had resulted in her husband leaving:

P8: He's a Spaniard and his mother would tell him I was going to take advantage of him because I was foreign... It's because the people from 
here are very racist. They see you are not from here and they won't accept you.

The Latinas' responses revealed that racism was more likely to be experienced by those with darker skin. Participant 13's words indicated that she thought racism was directed toward her due to her dark complexion.

P13: What I see here is that people are very racist. Here, I've had to stand in long lines at the bank while pregnant. In my country, priority is given to those who are pregnant. Spaniards see us as blacks coming to invade their country.

Participant 9 mentioned that a reason she had not experienced any racism since immigrating might be her lighter skin pigmentation:

P9: I have not had any problems. Maybe it has not occurred because of my skin complexion. If my features were more of those similar to what normally is associated with my country, maybe I would have been rejected.

\section{OPPORTUNITIES}

A notable outcome of the study was that, despite their diverse challenges, none of the Latinas indicated that she intended or even wished to return to her country of origin. On the contrary, all had apparently decided to stay in Spain. The women's responses strongly suggest that this was likely due to their believing that there were more opportunities for them and their children if they remained in Spain rather than returning to their Latin American country of origin.

\section{Opportunities for the Latinas' Children}

Several of the immigrant women mentioned the term opportunities explicitly. Three participants clearly indicated their belief that there were better opportunities for their children in Spain. Participant 6 stated:

P6: I always saw myself when older returning to the Dominican Republic, living in a wooden home, but not anymore. I have 
two daughters and I know they can have better opportunities here.

Participant 9 revealed a similar belief:

P9: In Europe, generally there are more opportunities. For the good of my child, I think Europe is the best option.

Participant 7 specifically mentioned the availability of better educational opportunities for her children in Spain:

P7: Here, they [children] can choose different habits [pathways] depending on the education you give them; but in my country it does not matter how much education you give them, sometimes they turn and take a different route. I decided to stay here with them because I had two children here. One is ten years old and the girl is eight. Here, the education is different from my country.

\section{Increased Safety}

In response to questions about their reason for immigrating and their views about living in Asturias, a number of the Latinas referred to the lower level of crime in Spain compared to their country of origin. For instance, in responding to the question of why she had immigrated, Participant 2 stated the following.

P2: Because I have family here, and the situation in Peru is not all that good. There's a lot of crime, and my sisters did not want to see me involved in any of that.

Participant 7 also mentioned the amount of crime in her country of origin as a reason for immigrating to Spain:

P7: In my country [Dominican Republic] there is a lot of crime. Having children over there is a problem.

When asked if she felt at home in Asturias, Participant 3 responded positively, comparing her life in Asturias, Spain, to the situation in her country of origin in regard to violence: 
P3: I feel very good in Asturias. The differences between the two countries are enormous. In Colombia there's a lot of violence. Here my life is more comfortable and peaceful.

Participant 5, in response to being asked whether she felt that life was good in Asturias, remarked:

P5: Yes, I've always liked living in Asturias. Here we can be out in the streets without having to worry. In other countries you always have to be watching who is coming behind you. Here everything is quiet and normal. There's everything [everything one needs], but you don't see the crime that there is in other places.

When asked if she thought her life would be better in her country of origin, Participant 10's response indicated that she felt it would not. She cited both the relative absence of crime and the better educational opportunities in Spain.

P10: If I had a father and mother, I would be very well, spiritually, but I will also tell you it is very difficult to raise a child in Brazil. There is a lot of crime and insecurity. Here, education is very good, and it opens a lot of doors. Here there are also a lot of bad people, but there are more opportunities.

\section{Greater Personal Independence}

A third type of perceived opportunity that was reflected in the remarks of several of the interviewed Latinas was the greater independence that living in Spain provided them in contrast to the relatively restricted roles available in their Latin American country of origin. The Latinas spoke positively of this relative independence. For instance, Participant 2 detailed her perception of being a mother in her country of origin compared to fulfilling the same role in Spain.

P2: Mothers in Peru are very submissive. I wouldn't like to be in their place. I am very proud to be Peruvian, but I do not like the role the mothers have in Peru. They are enslaved; they are only expected to take care of their children and their husbands. They are not permitted to have other ambitions. Here it is permitted. Here, women do other 
things: they go to the gym, the salon, they go have drinks with their friends. In Peru you drop off the children at school and right after you have to return to the house to attend to the husband, make food, do laundry-you don't have time for yourself.

Participant 9 compared the role of being a mother in Spain favorably to the situation in Peru, her country of origin. Her comments suggested that she planned on using her relative independence to develop a career in Spain.

P9: In Latin America, a mother always has to be at home with their children. Here things are different. Women are more independent. Many don't have kids past thirty. Many have children, but that does not mean they have to give up their career. I am Peruvian, but I don't believe my life has to be focused on my children. I would like to be working and going to school too.

Participant 6 remarked on having taken advantage of her independence in Spain since she was a teenager.

P6: Over there, women are at home waiting for the husband to bring the money in. Here, I have been independent since I was seventeen years old. I believe men and women should contribute money to the household; nobody should have to depend on anyone else financially. I have a cousin who totally depends on her husband, but also does not want to change. She is very close minded. I don't like that.

Participant 5 also remarked on the difference between Spain and her country of origin in regard to women's independence, saying that Latin women were "very dependent on their partner." When asked what she would consider to be her ideal role, this participant reported her desire to be a woman who was not as dependent on her husband as was customary in her former country.

P5: Being independent, not depending so much on the husband and ... giving an example to the kids of how to be independent and not to depend on another person, that we can take care of ourselves.

A remark by Participant 4 made clear that she did not approve of her mother's negative attitude toward women being independent and having interests outside the home, suggesting that she was in favor of the greater independence for women offered by Spanish society. 
P4: My mother is very close-minded. She believes women should be dedicated to the home and that going out to meet people is a form of disrespecting the family. She does not feel that getting to know people is normal.

When asked whether she believed that mothers in Asturias were more independent than those in Latin America, Participant 3, who was in school at the time of the interview, replied positively, suggesting that she considered her work at home to be due to free choice, not one that was culturally forced upon her.

P3: Yes. Over there, moms have to take care of the children, home, and their husbands - everything. Although I have not lived any of that [experienced any pressure like that]. Yes, I do take care of the chores at home, but no one obligates me to do so.

\section{DISCUSSION}

The interviews with 13 Latina immigrants to Spain revealed that these women faced diverse post-immigration challenges, while they also perceived that they benefited from various opportunities in Spain. Difficulties included personal and economic challenges. Some also reported being the targets of racist attitudes.

The women's economic challenges support Solé and Parella's (2003) finding that, in Spain, labor discrimination against immigrants occurs in terms of securing jobs, types of jobs, and working conditions, with discriminatory practices occurring regardless of immigrants' education, qualifications, or experience. Though immigrants to Spain have a relatively low risk of unemployment, they have a considerably higher risk of being employed in lowwage jobs than native Spanish citizens (Fellini 2017). Gaye and Jha (2011) note that immigrant women, who often have fewer job skills than non-migrants, tend to take low-skilled jobs in manufacturing or services, earning low wages, as was evident for several of the participants in this study. Being undocumented, which was mentioned by four of the interviewed Latinas, is another determinant that channels immigrant women into lower-paying jobs (Flippen 2014).

Working in low-paying jobs not only adversely affects immigrant women's empowerment but leaves them more vulnerable to work-related exploitation, which may have occurred to two women in this study who brought up the subject in their comments. Being an immigrant woman, especially one in a precarious 
economic situation, is a risk factor that increases the probability of work-related exploitation. Such exploitation may include paying wages under the legal minimum or no wages at all, requiring very long working hours, providing no days off, or demanding the worker pay taxes that are the legal responsibility of the employer (Leotti et al. 2014).

Another type of challenge reported by the Latinas was experiencing racism. Racist attitudes and behavior are often directed at a nation's immigrants simply because their country of origin is different from the one they have entered. Racism can be connected to the concept of the nation-state and nationalism (Yuval-Davis, 1996). Being a citizen of a nation-state, which is defined by physical boundaries around a geographic region, promotes identification with and allegiance to one's own nation. This allegiance may foster prejudice toward minorities whose origin is beyond the nation-state, especially if they are perceived as being different from the norm physically or linguistically. For several Latina immigrants in this study, having darker skin than the norm was thought to be a feature that invited racist attitudes from native Spaniards.

One result of racism toward immigrants is their relative ostracization from society and exclusion from important resources (Yuval-Davis, 1996). VásquezRoa (2018) relates such exclusion to the concept of borders. Migrants who have crossed the physical border surrounding a nation may still encounter internal borders constructed by society. These internal borders may limit the exercise of rights by migrants, restrict their access to services, and make it difficult to move around in public space, thereby hindering their active participation in and integration into society. Internally constructed borders may especially affect migrants who have not gained legal status, as was the case for the study's four undocumented participants. Even traversing from one location to another may pose problems for migrants without legal residency due to fear of being apprehended and deported. For these reasons, irregular migrants may try to remain relatively invisible within society. Feeling restricted by society's internal borders may have raised further challenges for the undocumented participants in this study, though they did not give voice to such concerns.

The racism that several of the participants experienced or witnessed occurred in the form of remarks or other behavior. Others did not report experiencing or witnessing overt racist behavior. Unfortunately, we cannot conclude from the latter finding that these other Latinas were not subject to aversive racism. This more hidden type of racism may be exhibited by people who do not practice overt racism, and who claim they are not racist at all. Aversive racism was detected among a sample of Spanish university students who favored a nativeborn Spaniard over a Latino immigrant from Mexico in a résumé assessment exercise, even though the two résumés were alike (Wojcieszak, 2015). This 
more subtle type of racism may be practically undetectable but could result in Latina immigrants being targets for unfavorable hiring practices even among employers who sincerely deny any prejudice against immigrants.

The interviews also revealed that the women believed that living in Spain provided advantages in comparison to living in their country of origin. These included better opportunities for their children, greater safety, and increased personal independence. The Latinas' perceptions of the greater opportunities of living in Spain likely explained their choosing to remain in their new country despite the challenges they encountered.

The perception that their children would receive a better education in Spain was one primary advantage that likely motivated the Latinas to stay in Spain. Their judgment is supported by data concerning the enrollment of children in schools in Spain in 2017 compared to recent figures in the interviewees' countries of origin, which indicate that children's education is more universally implemented in Spain. Whereas in Spain 97 percent of primary-school-aged children were enrolled in primary school in 2017, figures for Brazil, Colombia, Dominican Republic, Ecuador, Guatemala, and Peru for 2017 or 2018 show that primary school enrollment was 96, 93, 93, 92, 97, 87, and 96 percent, respectively (The World Bank Group 2019a). Even greater discrepancies exist between Spain and the Latin American countries in connection to secondary education enrollment. In Spain, net secondary enrollment was 97 percent in 2017, while the latest secondary net enrollment figures (for 2017 or 2018) for Brazil, Colombia, Dominican Republic, Ecuador, Guatemala, and Peru were $82,77,70,85,44$, and 89 percent, respectively (The World Bank Group 2019b). Given these figures and the Latinas' remarks, a main problem with education in their countries of origin may have been that the social and cultural context made it more difficult for children there to stay in school.

Regarding safety, the Latinas' responses gave evidence of a strong desire not to be subjected to criminal activity. World Bank data for 2014 indicate that 8.1 percent of Latin American and Caribbean residents feel very unsafe at home, compared to 1.1 percent of residents in developed countries (Baliki 2014), and no region in the world has a higher homicide rate than Latin America (Imbusch et al. 2011). Though not all study participants compared Spain to their home country regarding safety, none suggested that they believed life in Spain was less safe or more violent than in their country of origin. It is understandable that living in a country less racked by violence and crime would be a strong motivator for these women.

The Latinas' comments indicated that nearly half of them felt that women had greater personal independence than in their home country. These women all embraced their freer role and indicated that in Spain they would not settle for 
being limited to the traditional, Latin American restrictive definition of being a wife and mother. The finding that greater independence was perceived as an advantage by several of the participants agrees with the results of another study in which Latina immigrants recognized that their gender role in Spain had changed from the more rigid roles in Latin America (González-Juárez et al. 2014). In that study, researchers found that immigrant women felt there was greater freedom in Spain with respect to personal freedom, partner communication, and power in the family. These and the present study's observations are consistent with the results of a study by Campaña et al. (2015) showing that in Ecuador and Peru, the sending countries of six of this study's participants, women spent significantly more hours a week than men doing unpaid housework and caring for children. The differences occurred at three different education levels for women and men: primary (less than high school), secondary (high school), and more than high school, and for households both without and with children. In Ecuador, women with a primary education and children spent more time than men on such activity at a ratio of almost 5 to 1 . In Peru, the ratio was 3 to 1 . In Spain, the difference between women and men in terms of time spent on household work is considerably less, at a ratio of 1.9 to 1 (Gómez - Delgado 2018). The finding that Spanish men take on more unpaid household responsibilities may be attributed to the difference in the Spanish and Latin America cultures. In the latter, a predominant idea is that men and women have very different roles, with men going outside the home to work and women staying at home to care for the household and any children. Such a traditional view of the different roles of men and women can be expected to result in women spending more hours on unpaid household work than men (Balcells I Ventura 2009). In contrast, in Spain, there has been a strong movement towards greater equality between men and women over the past few decades. This has resulted in a law mandating that men should contribute equally to household chores and parenting duties (Nolan - Scott 2006). Though gender equality in terms of home-related responsibilities has not been achieved in Spain, the Global Gender Gap Report of the World Economic Forum (2020) lists Spain as among the top 10 nations for gender equity.

The findings of this study can be viewed from the perspective of the empowerment of immigrant Latina mothers in Spain. Generally, the empowerment of women can be considered as consisting of five types: economic, educational, social, political, and psychological (Mandal 2013). In regard to the first of these types, the majority of the study participants enjoyed little in the way of economic empowerment. Most of the Latinas who were working were relegated to low-paying jobs, which has a negative effect on economic empowerment (Gaye - Jha 2011). Immigrant women's economic empowerment is also adversely impacted by restrictions on the ability to secure 
jobs experienced by those who are undocumented (Flippen 2014), as was the case for two of the women in this study. Being exploited at work, which may have happened to at least two of the interviewed Latinas, also obviously runs counter to economic empowerment.

As for educational empowerment, two of the immigrant women reported having completed or being currently enrolled in classes, but most did not. However, it was clear from various statements that the women believed that educational opportunities for their children were better in Spain than in their country of origin, and these Latinas presumably believed that their immigrating to Spain would help strengthen their children's educational empowerment.

Social empowerment, in terms of strength of social relations and social structures, did not appear to be great for the Latina mothers in this study, as most were dealing with economic issues and the necessities of caring for their child or children. Social empowerment was probably negatively impacted by stereotyping and racist attitudes towards the women who experienced such attitudes. As for political empowerment, there was no evidence that the Latinas in the study had any substantial involvement in political structures. Thus, their political empowerment appeared to be minor.

The single area of empowerment in which most of the immigrant women in this study arguably showed considerable strength is psychological empowerment. This is evident first from the fact that the women made the choice to leave their country of origin and migrate to a new land. In making that choice, they, like many other migrants, displayed courage, the ability to take risks, and the willingness to open themselves to new experience (Adler - Gielen 2003), which are all characteristics that can be considered to be psychological strengths. Also, in the face of the challenges they experienced, all of the Latinas displayed perseverance and resilience. Several of them reported that they were "moving forward" (adalante) to describe their situation, indicating their determination to make a life for themselves and their children in Spain. A factor that likely added to their psychological empowerment was the fact that they were mothers or expectant mothers with the important responsibility of caring for the wellbeing and future of their child or children. Their recognition of the increase in opportunities their children would enjoy in Spain and their understanding that Spain provided a safer environment in which their children could come of age very plausibly strengthened the women's psychological resolve to persist in their new land. Even those who had encountered racist attitudes - experiences that can adversely affect immigrant Latinas' self-perceptions (Telzer - Vazquez Garcia 2009) - appeared, from their comments, to have considerable resilience and perseverance. Further evidence of the psychological empowerment of several of the interviewed Latinas was the positive attitude they revealed toward 
the greater independence for mothers and all women that they perceived was possible in Spain.

In summary, this study has offered evidence that many Latina immigrants to Spain encounter personal and economic challenges, as well as social challenges in the form of prejudice. However, the women believed that the opportunities of living in Spain, including expanded educational opportunities for their children, improved safety from crime, and the greater independence of women, exceeded those in their countries of origin. It is likely that the women recognized that, on balance, these greater opportunities outweighed the difficulties they had experienced and strengthened their resolve to remain in their new homeland.

\section{REFERENCES}

Adler, Lenore - Uwe Gielen (2003), "Preface". In: Lenore Adler - Uwe Gielen: Migration: Immigration and emigration in international perspective. Westport, CT, USA, Praeger, pp. xii-xv.

Balcells i Ventura, Laia (2009), "Analyzing the division of household labor within Spanish families", Revista Internacional de Sociología, Vol. 67, No. 1, pp. 83-105, DOI: 10.3989/ris.2009.11.123

Baliki, Ghassan (2014), "Crime and Victimization" Background note for the World Development Report 2014: Risk and Opportunity https:// openknowledge.worldbank.org/bitstream/handle/10986/16342/WDR14_bn Crime_and_Violence_Baliki.pdf?sequence $=1 \&$ isAllowed $=\mathrm{y}$ Last accessed: 04162020

Campaña, Juan et al. (2015), "Gender differences in the distribution of total work-time of Latin- American families. The importance of social norms", Munich Personal RePEc Archive Paper 62759. https://mpra.ub.uni-muenchen. de/62759/1/MPRA_paper_62759.pdf Last accessed: 03142020

Creswell, John - Vicki Plano Clark (2007), Designing and Conducting Mixed Methods Research, Thousand Oaks, CA, USA, Sage Publications.

Datosmacro.com (n.d.) Expansión. Spain-Immigration. https://datosmacro. expansion.com/demografia/migracion/inmigracion/espana Last access: 12 272019

Di Bartolomeo, Anna et al. (2008), "The labour market insertion of immigrants into Italy, Spain, and the United Kingdom", in: Elena Ambrosetti et al.: Migration in the Mediterranean. Socio-economic Perspectives. London, Routledge, pp. 57-84. 
Eurostat (2019), Migration and migrant population statistics. https:// ec.europa.eu/eurostat/statistics-explained/pdfscache/1275.pdf Last access: 12272019

Flippen, Chenoa (2014), "Intersectionality at work. Determinants of labor supply among immigrant Latinas", Gender \& Society, Vol 28, No 3, pp. 404434, DOI: $10.1177 / 0891243213504032$

Gaye, Amie - Shreyasi Jha (2011), "Measuring women's empowerment through migration", Diversities, Vol. 13, No. 1, pp. 49-66. https://unesdoc.unesco.org/ ark:/48223/pf0000191499.nameddest=191551 Last access: 12272019

Gómez, Manuel - Cristina Delgado (February 13, 2018), "Women spend twice as many hours as men on unpaid work", El País Newsletter.

https://elpais.com/economia/2018/02/12/actualidad/1518462534_348194.html Last access: 03142010

González-Juarez, Liliana et al. (2014), "Immigration experience of Latin American working women in Alicante, Spain. An ethnographic study", Revista Latino-Americana de Enfermagem. Vol. 22, No. 5, pp. 857-865, DOI: 10.1590/0104-1169.3559.2490

Imbusch et al. (2011), "Violence research in Latin America and the Caribbean. A literature review", International Journal of Conflict and Violence, Vol 5, No. 1, pp. 87-154, DOI: 10.4119/ijcv-2851

Instituto Nacional de Estadística (2018), Population figures at 1 January 2018. Migrations statistics. Year 2017. https:/www.ine.es/en/prensa/cp_e2018_p_ en.pdf Last Access: 12272019

Leotti, Paolo et al. (2014), Severe forms of labour exploitation. Supporting victims of severe forms of labour exploitation in having access to justice in EU Member States. Spain, 2014. European Union Agency for Fundamental Rights (FRA).https://fra.europa.eu/sites/default/files/fra_uploads/severelabour-exploitation-country_es.pdf Last access: 12272019

Mandal, Keshab (2013), "Concept and types of women empowerment", International Forum of Teaching and Studies, Vol. 9, No. 2, pp. 17-30. http://americanscholarspress.us/journals/IFST/pdf/IFOTS-2-2013/IFOTS_v9 n2_art3.pdf Last access: 12272019

Nolan, Jane - Jacqueline Scott (2006), "Gender and kinship in contemporary Britain”, In: Fatemeh Ebtehaj et al. (eds.): Kinship Matters. Oxford UK, Hart Publishing, pp. 175-194.

Patton, Michael (2002), Qualitative Research and Evaluation Methods (3rd ed.), Thousand Oaks, CA, USA, Sage Publications.

Rodríguez-Ibáñez, José (2006), "Emigrants in 20th century Spanish politics and culture", In: Raymond Rocco - Fernando García (eds.): Transnationalism. Issues and Perspectives. Madrid, Editorial Complutense, pp. 337-345. 
Solé, Carlotta - Sonia Parella (2003), "The labour market and racial discrimination in Spain", Journal of Ethnic and Migration Studies, Vol. 29, No. 1, pp. 121-140, DOI: 10.1080/1369183032000076759

Telzer, Eva - Heidie Vazquez Garcia (2009), "Skin color and self-perceptions of immigrant and U.S.-born Latinas: The moderating role of racial socialization and ethnic identity", Hispanic Journal of Behavioral Sciences, Vol. 31, No. 3, pp. 357-374, DOI: 10.1177/0739986309336913.

The World Bank Group (2019a), School enrollment, primary (\% net). https:// data.worldbank.org/indicator/SE.PRM.NENR Last access: 03142020

The World Bank Group (2019b), School enrollment, secondary (\% net). https:// data.worldbank.org/indicator/SE.SEC.NENR Last access: 03142020

Vásquez-Roa, Laura (2018), "Navigating and negotiating the city. Irregular migrants' experiences with borderscapes in Madrid, Spain. Antípoda", Revista de Antropología y Arqueología, Vol. 32, pp. 81-103. https://doi.org/10.7440/ antipoda32.2018.04 Last access: 12272019

Wildsmith, Elizabeth - Kelly Raley (2006), "Race-ethnic differences in nonmarital fertility. A focus on Mexican American women", Journal of Marriage and Family, Vol. 68, No. 2, pp. 491-508. DOI: 10.1111/j.17413737.2006.00267.x

Wojcieszak, Magdalena (2015), "Aversive racism in Spain. Testing the theory", International Journal of Public Opinion Research, Vol. 27, No. 1, pp. 22-45. DOI: 10.1093/ijpor/edu007

World Economic Forum (2020), Mind the 100 year gap. https://www.weforum. org/reports/gender-gap-2020-report-100-years-pay-equality Last access: 03 142020

Yuval-Davis, Nira (1996), Gender \& Nation, London, Sage Publications.

Zlotnik, Hania (2003), The global dimensions of female migration. https://www. migrationpolicy.org/article/global-dimensions-female-migration Last access: 12272019 
